\title{
Comparative $\mathrm{H}_{2} \mathrm{~S}$ Sensing Characteristics of $\mathrm{Fe}_{2} \mathrm{O}_{3}$ : Thin Film vs. Bulk
}

\author{
Vishal Balouria ${ }^{1,2}$, Ajay Singh ${ }^{1}$, Niranjan Suryakant Ramgir ${ }^{1}$, Anil Krishan Debnath ${ }^{1}$, \\ Aman Mahajan ${ }^{2}$, Ratish Kumar Bedi ${ }^{2}$, Dinesh Kumar Aswal ${ }^{1}$, Shiv Kumar Gupta ${ }^{1}$ \\ ${ }^{1}$ Technical Physics Division, Bhabha Atomic Research Center, Mumbai, India; ${ }^{2}$ Material Science Laboratory, Department of Physics, \\ Guru Nanak Dev University, Amritsar, India. \\ Email: vishalbalouria@yahoo.com
}

Received October $1^{\text {st }}, 2013$; revised November $2^{\text {nd }}, 2013$; accepted November $9^{\text {th }}, 2013$

Copyright (C) 2013 Vishal Balouria et al. This is an open access article distributed under the Creative Commons Attribution License, which permits unrestricted use, distribution, and reproduction in any medium, provided the original work is properly cited.

\begin{abstract}
Comparative investigations of gas sensing characteristics of $\mathrm{Fe}_{2} \mathrm{O}_{3}$ in both thin film as well as bulk forms have been performed. Thin film sensors were realized by first depositing Fe films using electron-beam evaporation followed by thermal oxidation. Bulk sensors in the form of pellets were prepared by cold pressing commercial $\mathrm{Fe}_{2} \mathrm{O}_{3}$ powder with subsequent sintering. Both thin film and bulk $\mathrm{Fe}_{2} \mathrm{O}_{3}$ sensors exhibited a selective and reversible response characteristics towards $\mathrm{H}_{2} \mathrm{~S}$ with maximum response at an operating temperature of $250^{\circ} \mathrm{C}$ and $200^{\circ} \mathrm{C}$, respectively. A negligible response towards other interfering gases was observed. Thin film sensors exhibited an enhanced response in comparison to that of pellets.
\end{abstract}

Keywords: $\mathrm{Fe}_{2} \mathrm{O}_{3}$; Thin Film; Pellets; $\mathrm{H}_{2} \mathrm{~S}$ Sensor

\section{Introduction}

$\mathrm{H}_{2} \mathrm{~S}$ is a colorless, highly flammable and toxic gas, which in low concentration has an offensive odor similar to that of rotten eggs. As the Threshold Limit Value (TLV) for $\mathrm{H}_{2} \mathrm{~S}$ is $10 \mathrm{ppm}$, there is a need for its detection in either ppm or sub ppm level [1-3]. $\alpha-\mathrm{Fe}_{2} \mathrm{O}_{3}$, an intrinsically n-type semiconductor has been widely exploited as a gas sensitive material owing to its good structural and thermodynamical stability along with resistance to photocorrosion. In the present work, $\mathrm{H}_{2} \mathrm{~S}$ sensing characteristics of $\mathrm{Fe}_{2} \mathrm{O}_{3}$ in both thin film and conventional forms have been investigated and compared. Our results indicate that thin film based sensors exhibited better response towards $\mathrm{H}_{2} \mathrm{~S}$ in comparison to that of pellets.

\section{Experimental}

$\mathrm{Fe}_{2} \mathrm{O}_{3}$ thin films were prepared in two steps. In the first step, Fe films with $\sim 100 \mathrm{~nm}$ thickness were deposited onto pre-cleaned (0001) $\mathrm{Al}_{2} \mathrm{O}_{3}$ substrates using electron-beam evaporation under a base vacuum of $\sim 1.3 \times$ $10^{-4} \mathrm{~Pa}$. A high purity $(99.99 \%) \mathrm{Fe}$ powder was cold pressed in the form of a pellet and used as source material. These films were subsequently subjected to thermal oxidation at $800^{\circ} \mathrm{C}$ in an oxygen environment $\left(\mathrm{O}_{2}\right.$ flow: $50 \mathrm{sccm}$ ) for $2 \mathrm{~h}$. Bulk sensors in the form of pellets were prepared by cold pressing commercial $\mathrm{Fe}_{2} \mathrm{O}_{3}$ powder followed by sintering at $800^{\circ} \mathrm{C}$ for $2 \mathrm{~h}$. The response characteristics were recorded as a function of temperature, gas $\left(\mathrm{H}_{2} \mathrm{~S}, \mathrm{C}_{2} \mathrm{H}_{5} \mathrm{OH}, \mathrm{NH}_{3}, \mathrm{CH}_{4}, \mathrm{CO}, \mathrm{CO}_{2}, \mathrm{NO}\right.$, and $\mathrm{Cl}_{2}$ ) and their concentrations using a static setup as described elsewhere [4]. For this purpose, the sensor was mounted on a Pt-100 based heater assembly in a leaktight glass chamber (net volume: $500 \mathrm{ml}$ ). Electrical contacts were made by thermally depositing two Au pads (120 nm thick). A desired concentration of the test gas in the chamber was achieved by injecting a known quantity of the test gas using a micro-syringe. The sensor response was calculated using the relations:

$$
R \%=\left(\frac{G_{g}-G_{a}}{G_{a}}\right) \times 100
$$

where $G_{g}$ and $G_{a}$ are conductance in the presence of test gas and air, respectively.

\section{Results}

Figure 1 shows the X-ray diffraction (XRD) pattern ob- 


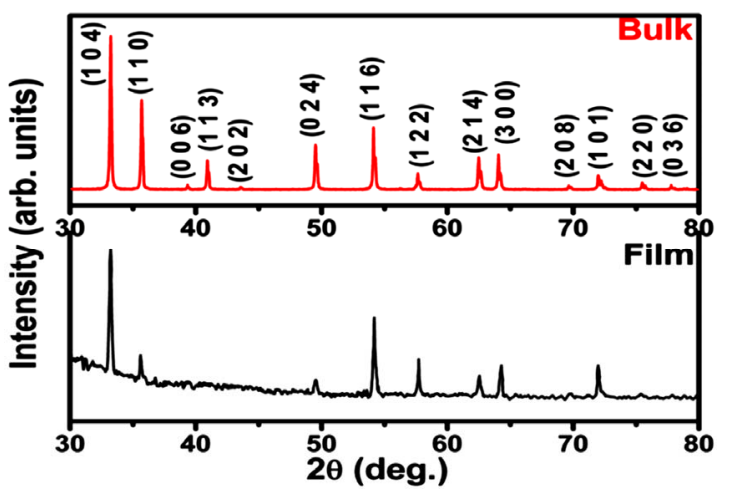

Figure 1. XRD diffraction pattern for $\mathrm{Fe}_{2} \mathrm{O}_{3}$ in bulk and thin film form.

tained for $\mathrm{Fe}_{2} \mathrm{O}_{3}$ thin film and bulk samples. All the peaks could be assigned to the single phase of $\mathrm{Fe}_{2} \mathrm{O}_{3}$ (hematite). The least-square fitting of the pattern indicated hexagonal rhombo-centred cubic unit cell structure with lattice parameters $\mathrm{a}=\mathrm{b}=5.028 \AA, \mathrm{c}=13.73$ and $\alpha=$ $\beta=90^{\circ}, \gamma=120^{\circ}$, which are in agreement with the reported values [JCPDS card no. \#79-0007].

Figure 2 is a plot of \% response recorded for both the sensor films as a function of operating temperature towards $10 \mathrm{ppm}$ of $\mathrm{H}_{2} \mathrm{~S}$. It is clearly evident that thin films and bulk sensors exhibit response maxima at $250^{\circ} \mathrm{C}$ and $200^{\circ} \mathrm{C}$, respectively. At all the temperatures the response of thin films is higher than that of bulk samples. For instance, thin film sensors show, response maxima of $262 \%$ in comparison to $112 \%$, exhibited by bulk samples towards $10 \mathrm{ppm} \mathrm{H}_{2} \mathrm{~S}$.

A Typical response curves for both the sensor films towards $10 \mathrm{ppm} \mathrm{H}_{2} \mathrm{~S}$ is shown in Figure 3. The conductance of the sensors increases on exposure to $\mathrm{H}_{2} \mathrm{~S}$ indicating an n-type response. Thin film sensors exhibited a maximum response towards $\mathrm{H}_{2} \mathrm{~S}$. A baseline drift was observed for bulk sensors.

Figure 4 shows the selectivity histogram recorded upon exposure to $10 \mathrm{ppm}$ of various reducing and oxidizing test gases. It is clearly evident that both the sensors are highly selective towards $\mathrm{H}_{2} \mathrm{~S}$. A negligible response towards all the other interfering gases was observed.

\section{Conclusion}

Comparative gas sensing properties of $\mathrm{Fe}_{2} \mathrm{O}_{3}$ in thin film and bulk form have been investigated. Both the sensor types exhibited an n-type response characteristic with highly selective response towards $\mathrm{H}_{2} \mathrm{~S}$. An operating temperature for maximum response towards $\mathrm{H}_{2} \mathrm{~S}$ was found to be $250^{\circ} \mathrm{C}$ and $200^{\circ} \mathrm{C}$ for thin film and bulk sensors, respectively. For $\mathrm{H}_{2} \mathrm{~S}$ detection, thin film is a better sensor in comparison to bulk owing to the enhanced response and less baseline drift.

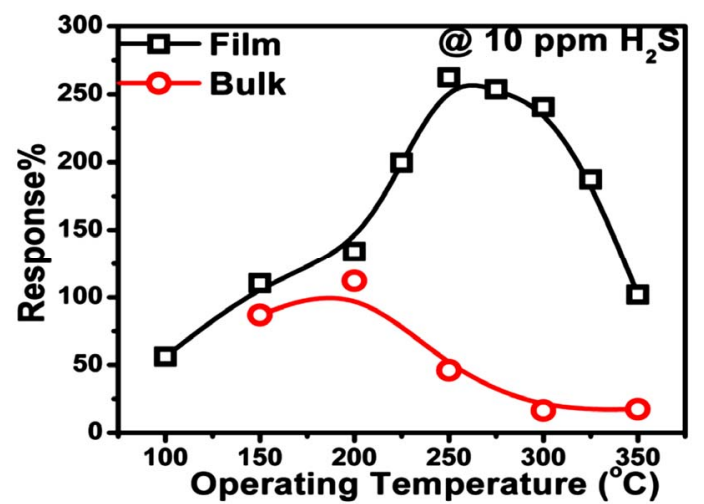

Figure 2. Sensor responses as a function of operating temperature.

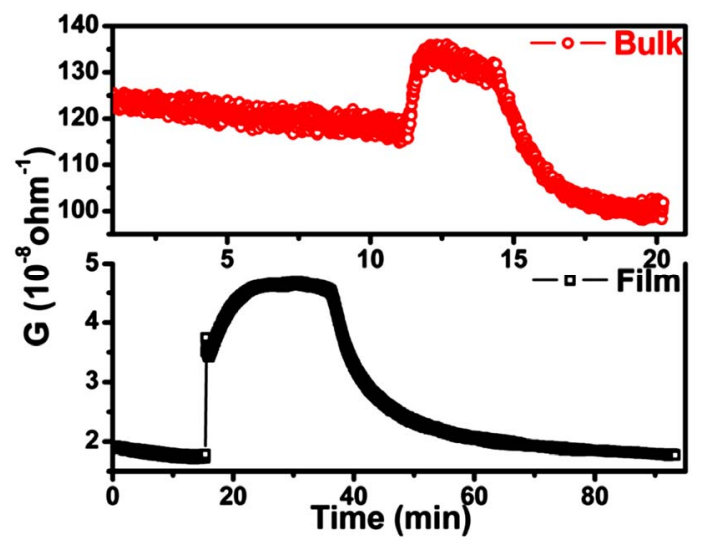

Figure 3. Sensor responses @ 10 ppm $\mathrm{H}_{2} \mathrm{~S}$ for bulk and thin film sensor.

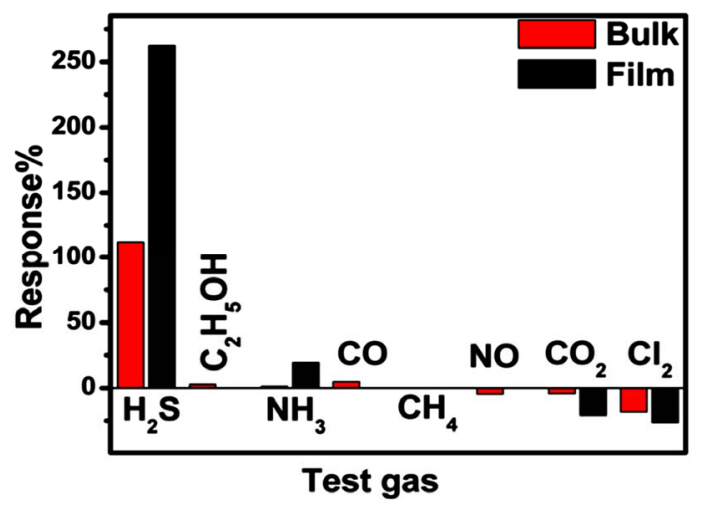

Figure 4. Selectivity data for bulk and thin films.

\section{Acknowledgements}

V.B. thanks CSIR, New Delhi for the senior research fellowship. The authors are thankful to BRNS-DAE for providing financial assistance vide Sanction No. 2008/ 37/4/BRNS.

\section{REFERENCES}

[1] M. Kaur, D. K. Aswal and J. V. Yakhmi, "Chemiresistor 
Gas Sensors: Materials, Mechanisms and Fabrication," In: D. K. Aswal and S. K. Gupta, Eds., Science and Technology of Chemiresistor Gas Sensors, Nova Science Publisher, New York, 2007, pp. 33-93.

[2] V. Balouria, A. Kumar, A. Singh, S. Samanta, A. K. Debnath, A. Mahajan, R. K. Bedi, D. K. Aswal, S. K. Gupta and J. V. Yakhmi, "Temperature Dependent $\mathrm{H}_{2} \mathrm{~S}$ and $\mathrm{Cl}_{2}$ Sensing Selectivity of $\mathrm{Cr}_{2} \mathrm{O}_{3}$ Thin Films," Sensors and Actuators B: Chemical, Vol. 157, No. 2, 2011, pp. 466-472. http://dx.doi.org/10.1016/j.snb.2011.05.002

[3] V. Balouria, S. Samanta, A. Singh, A. K. Debnath, A.
Mahajan, R. K. Bedi, D. K. Aswal, S. K. Gupta, "Chemiresistive Gas Sensing Properties of Nanocrystalline $\mathrm{Co}_{3} \mathrm{O}_{4}$ Thin Films," Sensors and Actuators B: Chemical, Vol. 176, 2013, pp. 38-45.

http://dx.doi.org/10.1016/j.snb.2012.08.064

[4] V. Balouria, A. Kumar, S. Samanta, A. Singh, A. K. Debnath, A. Mahajan, R. K. Bedi, D. K. Aswal, S. K. Gupta, "Nano-Crystalline $\mathrm{Fe}_{2} \mathrm{O}_{3}$ Thin Films for ppm Level Detection of $\mathrm{H}_{2} \mathrm{~S}$," Sensors and Actuators B: Chemical, Vol. 181, 2013, pp. 471-478.

http://dx.doi.org/10.1016/j.snb.2013.02.013 